تأئير وسائله التواصله الاجتماعي في التغيير السباسيه بالسودان

تأثير وسائل التواصل الاجتماعي في التفيير السياسي بـالسودان

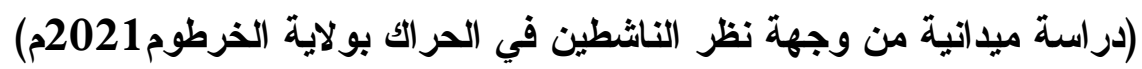

\title{
Effect of social media in political change in Sudan
}

(A field study from the point of view of activists in the

movement in the state of Khartoum 2021)

د. دار الدين علي حمد محمد*

Dr. Badereldin Ali Hamed Mohammed

doi.org/10.52981/cs.v6i3.182 مستخلص الدراسة:

جاعت هذه الدراسة بعنوان (تأثير وسائل التواصل الاجتماعي في التغيير السياسي بالسودان-

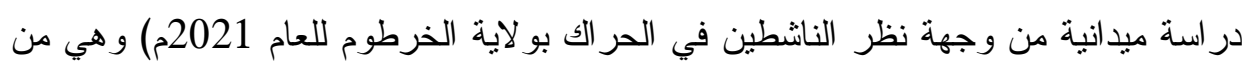

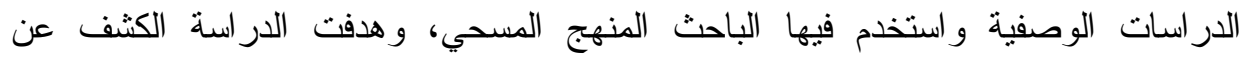

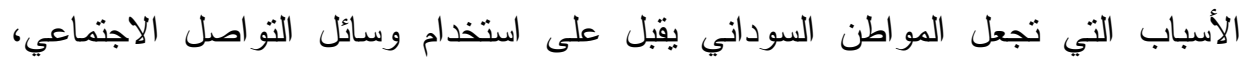

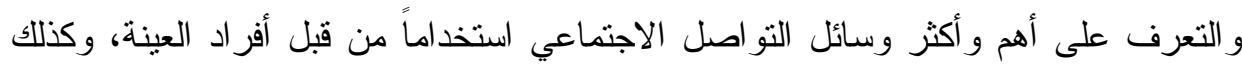

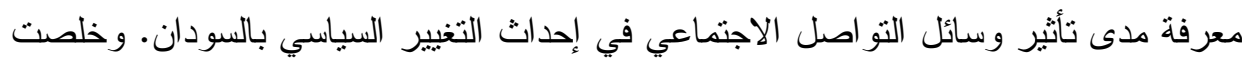

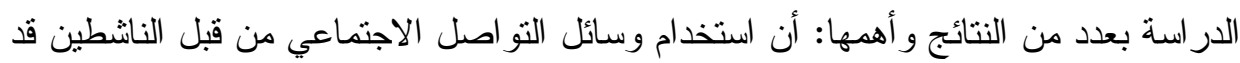

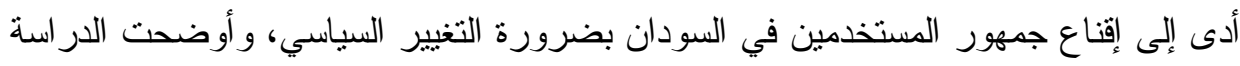
أن تجاهل أفراد السلطة الحاكمة لقوة تأثير وسائل التواصل الاجنماعي ساعد على التئي التغيير

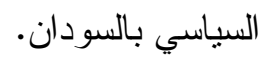

أكد أفر اد الدراسة على أن وسائل التواصل الاجتماعي لها تأثير كبير على الحر الك

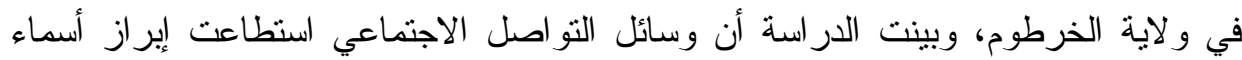

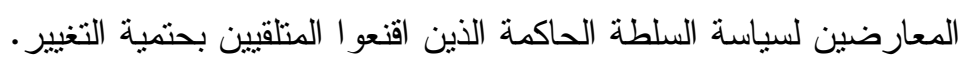
الكلمات المفتاحية: تأثير ، السياسي، التغيير، التواصل الاجتماعي، السودان.

* أستاذ مشارك بقسم الصحافة والإعلام بكلية الآداب والعلوم الإنسانية - جامعة جازان المملكة العربية السعودية

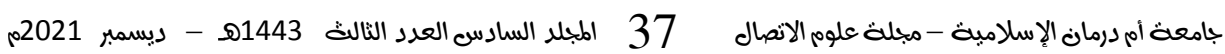


Abstract:

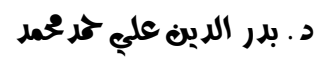

This study is entitled (Effect of social media in political change in Sudan - A field study from the point of view of activists in the movement in the state of Khartoum 2021 Type of study: Descriptive study is the methodology used is the survey method.

Objectives of the study: Disclosure of the reasons that make the Sudanese citizen accept the use of social media and Identification of the most important means of social communication used by members of the study, to know the impact of social media in the political change in Sudan. The most important results: the use of social media by activists has led to the response and conviction of the users of the Sudan need for political change.

The study showed that ignoring members of the ruling power of the influence of social media helped the political change in Sudan. confirmed the study members on the impact of the use of social media by users has helped to detect the types of corruption within the members of the ruling authority in Sudan

The study showed that the means of social communication was able to highlight the names of opponents of the policy of the ruling power, who convinced the recipients with the inevitability of change.

Keywords: Effect, political change, social media, Sudan

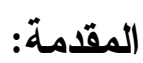

وسائل التواصل الاجتماعي ثقوم بدور بارز في الأحداث السياسية

و التغير ات السياسية، لم يقتصر دور وسائل التو اصل الاجتماعي في البلدان على

الاحتجاجات فقط، بل لعبت دوراً مهماً وو اضحاً في أوروبا و الولايات المتحدة

الأمريكية إذ قام سياسيون في هذه الدول باستخدام وسائل التو اصل الاجتماعي

في حملاتهم الانتخابية وفي التواصل مع الناخبين وفي الإعلان عن نشاطاتهم

ونشر تصريحاتهم بالتغريدات التي يثتهر بها (توتير) إذ يمكن التواصل مع هذا

الموقع بسهولة من خلا الهاتف الذكي،مما سهل وشجع عملية استخدامه في

النشاط السياسي سواء من قبل الكثير من السياسيين أم من قبل جمهور من

الناس، وقد قامت بعض الاحتجاجات في إيران في العام (2009م) وسميت

بثورة (توتير) وذلك على خلفية الانتخابات التي فاز بها الرئيس أحمد نجادي،

جامعة أم درمان الإسلامبة - مبلة علوم الانصال 38 م المجلد السادسه العدد الثاله 1443هـ - ديسمبر 2021م 
تأئير وسائل التواصل الاجتماعي في التغيير السباسهي بالسودان

و أطلق الكثيرون على ثورتي تونس ومصر بثور ات الفيس بوك نظر اً للاستخدام

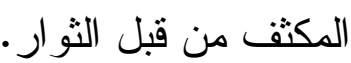

و السودان من بين هذه الدول التي تستخدم وسائل التو اصل الاجتماعي، وتتنوع هذه الاستخدامات مع طغيان الاستخدام السياسي على كثير من الاستخدامات، وفي هذه الدر اسة يتم تتاول تأثنير وسائل التو اصل الاجتماعي في السودان من وجهة نظر المستخدمين الناشطين في الحراك السياسي ومدى تفاعلهم مع الرسائل الإعلامية التي ترد عبر وسائل التو اصل الاجتماعي.

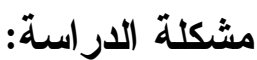

جاءت مشكلة الدراسة من خلا متابعة الباحث ل لوسائل التو اصل الاجتماعي و التي شهدت انتشارًا و استخدماً واسعاً في مدن السودان المختلفة، وكذلك من خلال نقلها لما يحدث من حر الك سياسي في السودان، ويمكن صياغة مشكلة الدر اسة في التقصي الدقيق لمعرفة تأثير وسائل التو اصل الاجتماعي على الوضع السياسي وما تحدثه من التغييرات السياسية، من خلال هذه العرض أرض لمشكلة الدر اسة يمكن أن تتمحور في السؤال الرئيس: ما تأثير وسائل التو اصل الاجتماعي في التغيير السياسي في السودان؟. تساؤلات الدراسة:

1- ما أكثر الأسباب التي تدعو لاستخدام وسائل التو اصل الاجتماعي؟

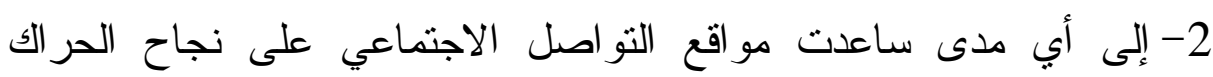

$$
\text { السياسي في السودان؟ }
$$

3- ما درجة الموافقة على أن وسائل التواصل الاجتماعي مكنت الناشطين

السياسيين في طر ح أفكار هم نحو التغيير السياسي بالسودان؟

جامعة أم درمان الإسلامبة - مجلة علوم الانصال 39 المجلد السادسه العدد النالة 1443هـ - دبسمبر 2021م 


\section{د. برر الربن علي حمرحمل}

4- ما درجة الموافقة على أن تجاهل السلطة الحاكمة لقوة تأثير وسائل

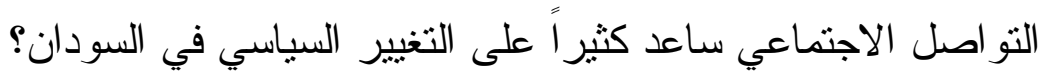

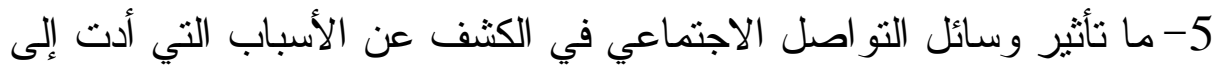

$$
\text { تغيير السلطة الحاكمة في السودان؟ }
$$

6- ما أكثر وسائل التواصل الاجتماعي التي ساعدت على التغيير السياسي في

$$
\text { السودان؟ }
$$

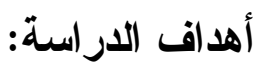

1- الكثف عن الأسباب الني تجعل المواطن السوداني يقبل على استخدام وسائل

$$
\text { التو اصل الاجتماعي. }
$$

2- التعرف على أكثر وسيلة من وسائل التواصل الاجتماعي استخداماً من أفراد

$$
\text { عينة الدر اسة. }
$$

3- معرفة مدى تأثثير وسائل التو اصل الاجتماعي في التغيير السياسي بالسودان.

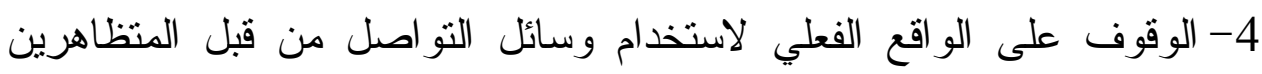

و النشطاء السياسيين و الذي ساعد على نجاح الحر الك السياسي في السودان.

$$
\text { أهمية الدر اسة: }
$$

تأتي أهمية الدراسة من خلال أهية وسائل التواصل الاجتماعي، وما تحدثه من تغييرات سياسية واجتماعية، ونرتكز هذه الدراسة لمعرفة تأثير سائل اهنيل التواصل الاجتماعي على المواطن السوداني. وكذلك معرفة توظيف استخدام هذه الوسائل في التغيير السياسي بالسودان من قبل المتظاهرين ومدى الاستفادة

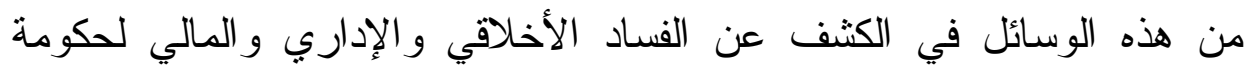
الإنقاذ بالسودان بالرغم من غياب الوسائل التقليدية كالإذاعة والتلفزيون

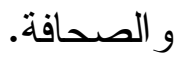


تأيثر وسائل التواصل الاجتماعي في التغيير السباسيه بالسودان

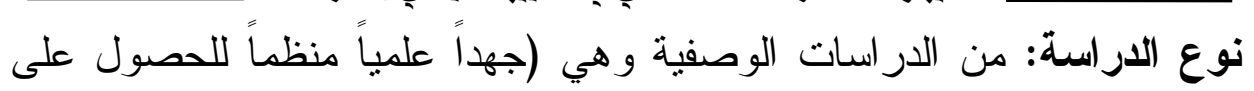

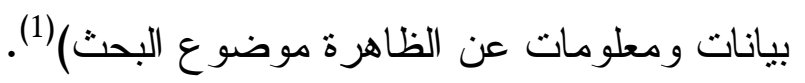
منهجية الاراسة: وهو المنهج المسحي في مجال الدراسات الوصفية و الذي يعرف بأنه أحد الأشكال الخاصة بجمع المعلومات عن الأفراد وسلوكه و اتجاهاتهم(2). ويفيد هذا المنهج في استخلاص نتائج من خلال دراسة عينة البحث، وبالتالي الوصول إلى تعميمات حول موضوع الدر اسة. حدود الار اسة: الحدود المكاتية: تشمل الحدود المكانية ولاية الخرطوم وقد تم اختيار ها لأنها العاصمة التي يزداد فيها التأثنر القوي للحر الك السياسي و أيضاً لاستقر ار شبكة الانترنيت.

الحدود الزمانية: اختار الباحث العام 2021م للوقوف على الو اقع الحالي لتأثير استخدام وسائل التو اصل الاجتماعي في التغيير السباسي في السودان، ونسبة للأحداث الاقتصادية و السياسية و الاجتماعية التي تحصل في كل فتزة من مطالبات في تغيير الحكومة أو إصلاح الوضع الاقتصادي وتشكيل المجالس التشريعية في البلاد. عينة الار اسلة:

تم اختيار عينة من النشطاء السياسيين الذين بستخدمون وسائل التواصل الاجتماعي بولاية الخرطوم عن طريق العينة القصدية وبلغ عددهم (420) مبحوث، فقد اختار الباحث جزئية منهم تمثل هذا المجتمع وتحدد أغر اض لإن

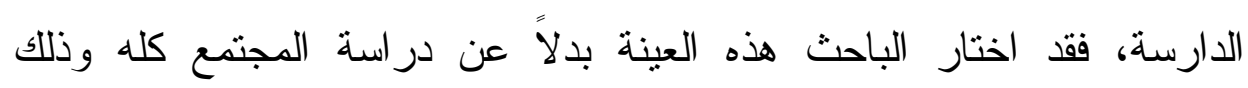

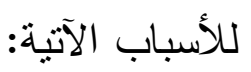

جامعة أم درمان الإسلامية - مجلة علوم الاتصال 41 المجلد السادسه العدد النالة 1443هـ - ديسمبر 2021م 


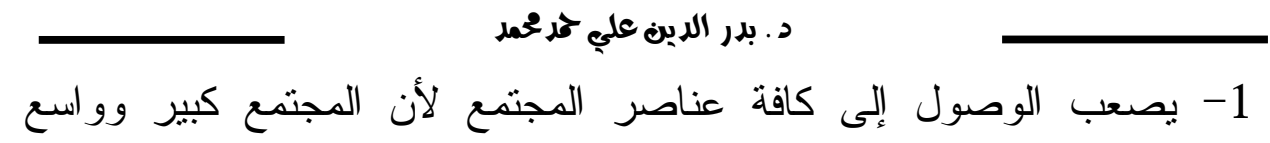
الانتشار .

2- يصعب تعميم دراسة الظاهرة على جميع المجتمع الأصلي وهو المستخدمون السودانيون.

وقد قام الباحث باختيار عينة ممثلة لمجتمع الدراسة لأن أفراد المجتمع متجانسون، ولذلك تم اختيار العينة القصدية وذلك بإعداد استمارة الاستبانة و إرسالها عن طريق الكمبيوتز ووضع رابط و إرسالها لأفر اد العينة وتعتبر عينة ممثلة غير منحازة وفيها جميع خصائص الجمهور الأصلي.

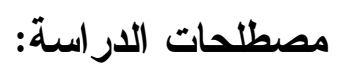

التأثير: هو إضافة حالة نفسية ناتجة عن إضافة أفكار جديدة لدى المتلقي تجعله عند تحركه مدفو عاً بهذه الحالة النفسية ومجموعة الأفكار و المعلومات التي لديه، ولهذه الحالة النفسية دور كبير في تغيير سلوك الإنسان لفترة معينة في اتجاهات معينة) (3) مهذه

التعريف الإجرائي: في هذه الدراسة يعني التأثنير في المستخدمين من قبل النشطاء المعارضين لحكومة الإنقاذ بالسودان في اعتمادهم على وسائل التو اصل الاجتماعي لطرح أفكار هم نحو ضرورة التغيير السياسي في السودان. التغييز السياسي: يشار إلبه بأنه مجمل التحولات التي قد تتعرض لها البني السياسية في المجتمع أو طبيعة العمليات السياسية، والتفاعلات بين القوى بله السياسية وتغيير الأهداف بما يعنيه كل ذلك على مر اكز القوة بحيث يعاد توزيع

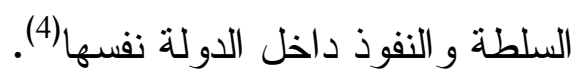
التعريف الإجرائي: في هذه الدراسة يعني التغيير السياسي استخدام الحر الك من مظاهرات و اعتصامات استمرت لأربعة شهور وتم فيها التغيير بسقوط نظام

$$
\text { الإنقاذ في السودان. }
$$


تأئير وسائل التواصل الاجتماعي في التغيير السباسيج بالسودان

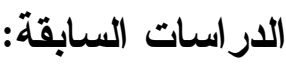

1- دراسة رباب رأفت محمد جمال (2013م)(5): نتتمي الدراسة للاراسات الوصفية واعتمدت على المنهج المسحي وكانت عينة الدر اسة عشو ائية متعددة المر احل من الثباب السعودي، وخرجت الدراسة بأهم النتائج وهي استخدام الثباب لثبكة الانترنيت بصورة مرتفعة ومعدل الثقة في شبكات التواصل

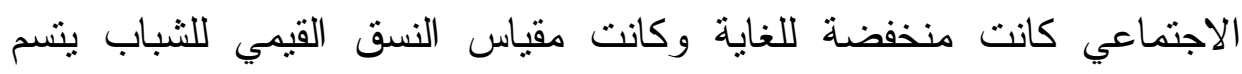

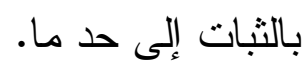

2- دراسة أسامة غازي مدني (2015م)(6): استخدمت في الدراسة المنهج الوصفي و اعتمدت على الأسلوب المسحي، وهدفت الدراسة إلى معرفة دور

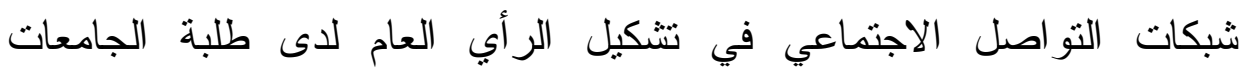

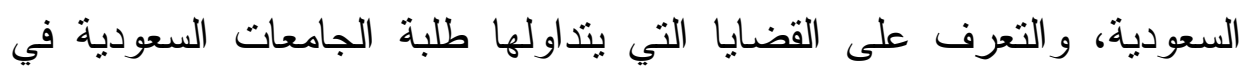

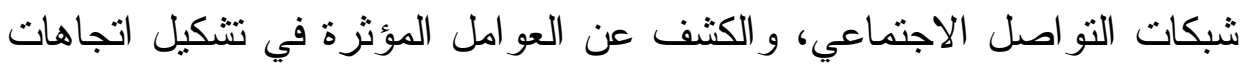

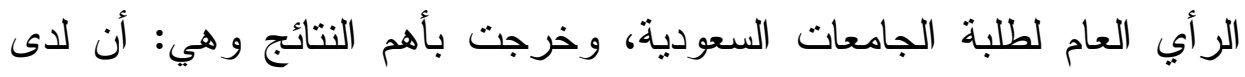
مستخدمي شبكة التواصل الاجتماعي مستويات مرتفعة من الوعي في التعامل

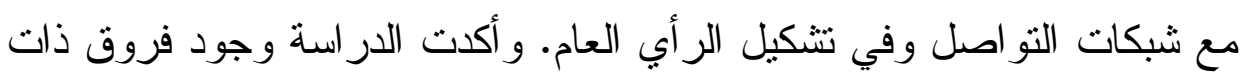

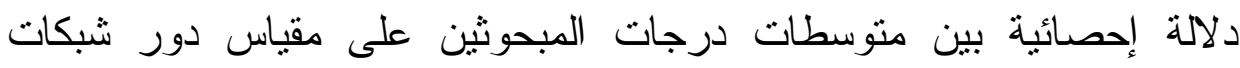

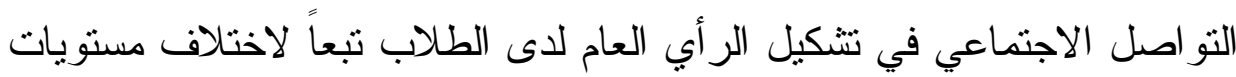
استخدام شبكات التو اصل الاجتماعي بينهم.

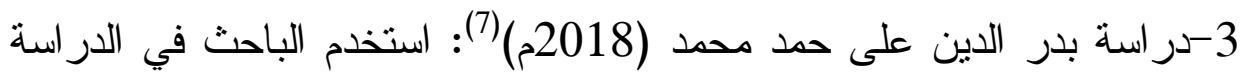

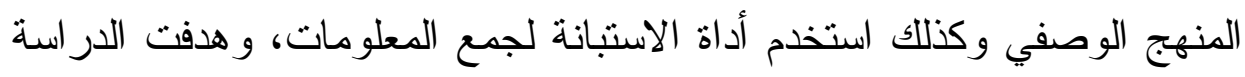

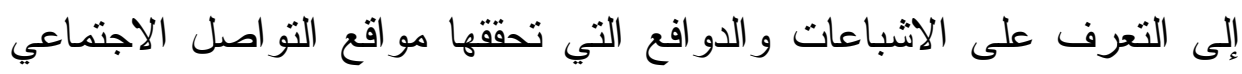
للمستخدمين في الكثف عن أنكال الانتهاكات من قبل مستخدمي مو اقع التو اصل

بامعة ام درمان الإسلامية - مبلة علوم الانصال 43 المبلد السادسم العدد النالغ 1443هـ - ديسمبر 2021م. 


\section{د. برر الربن علي حر حمدر}

نحو خصوصية المستخدمين الآخرين، وبالوقوف على الطرق التي يمكن أن يتم

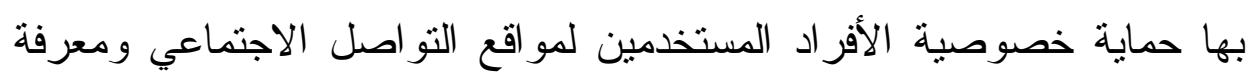

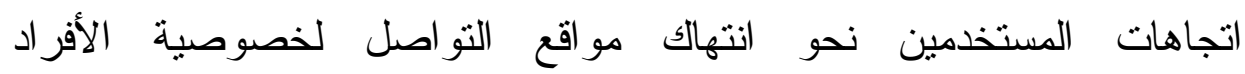

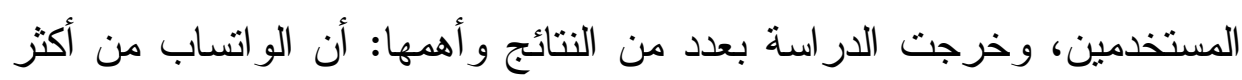

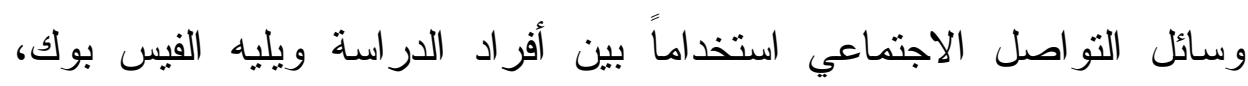

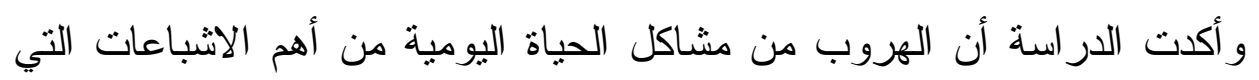

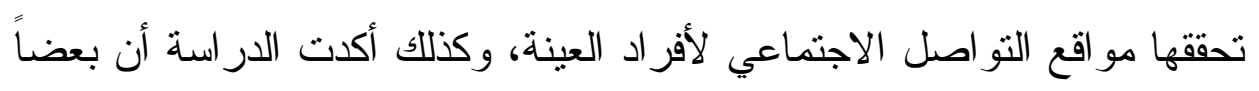

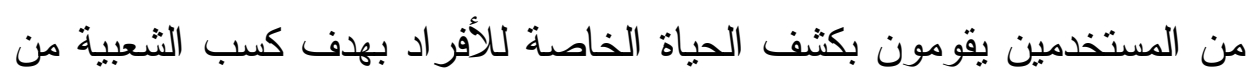

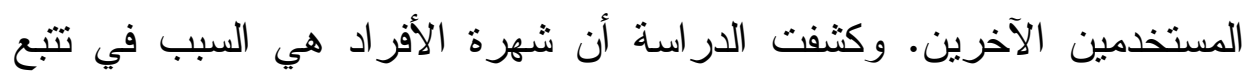

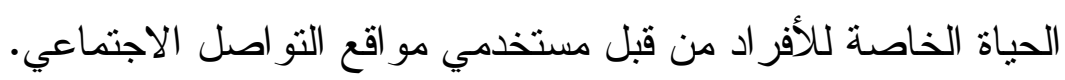

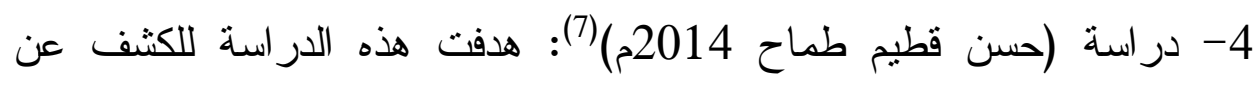
طبيعة الاستخدامات السياسية لتويتر، و إغراضها ومضامينها لإنها المختلفة واستخدم الباحث المنهج المسحي الوصفي وأداة الاستبانة التي طبقت على وإنى عينة (404) فرداً بطريقة العينة العشوائية ونوصلت لأهم النتائج التي من بينها:

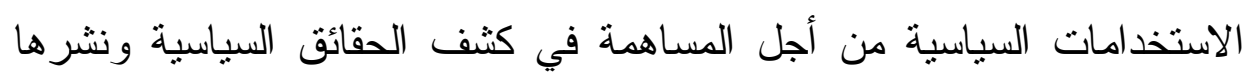

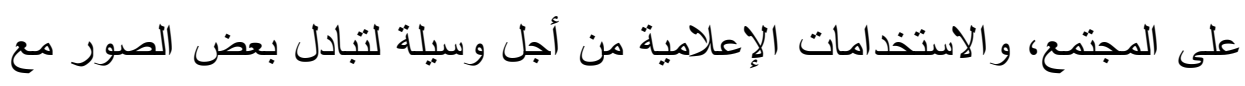
الأصدقاء و المعارف، و الكثف عن الفئه الفساد السياسي و الإداري.

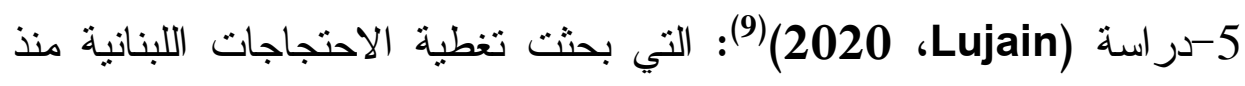

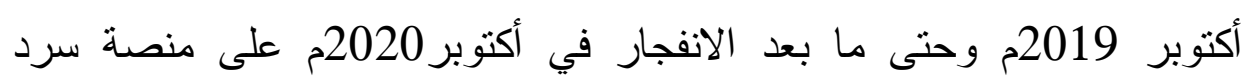
القصص TikTok، وسعت الدراسة إلى تحليل تأطير الاحتجاجات اللبنانية وشرحها بالرجوع إلى نموذج الاحتجاج و التحليل السردي و التقنيات الساخرة (الأربعة). 
حيث تم استخدام طريقة أخذ العينات الهادفة، و اعتمد البحث في تحليل محتواها وفق البيانات الأولية التي تم جمعها من خلال منصة التواصل الاجتماعي TikTok حيث أظهرت النتائج تصور ات و اسعة في إنشاء محتوى فكاهي فيما يتعلق بالجوانب الاجتماعية والاقتصادية و السياسية، فضلاً عن الاستخدام المنز ايد للروايات في مقاطع الفيديو، و أبرز أنو اع الأساليب الساخرة المستخدمة هي التتاقض، تليها المحاكاة الساخرة. ونوصلت الدراسة إلى أن هناك ميلاً أكبر لإنتاج مقاطع فيديو تتعلق بالانفجار لحداثته، بالإضافة إلى استمرار استخدام السخرية لانتقاد الدور السياسي في المجتمع، و هناك مساهمة كبيرة لمقاطع الفيديو الجادة التي تتقل الوعي بالنز اعات في لبنان على المنصة، مما يسلط الضوء على تتوع المحتوى على المنصة.

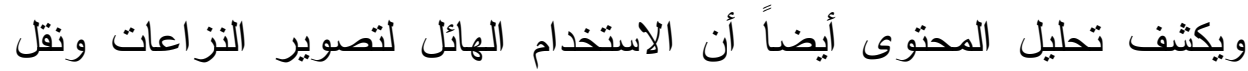
الأحداث سمح للمبدعين بالتحدث عن صر اعات معينة بأسلوب إبداعي خاص الص

\section{التعليق على الدراسات السابقة:}

يوجد شبه بين الدراسات السابقة وهذه الدراسة ويتمثل ذللك في تتاول وسائل التو اصل الاجتماعي ولكنها تختلف عن هذه الدراسات السابقة بأن هذه الدر اسات تتاولت وسائل التو اصل الاجتماعي في الخصوصية وفي الاحتجاجات، وفي الاستخدامات السياسية وفي تشكيل الرأي العام بينما هذه الدر اسة تتناول النأثنر لوسائل التو اصل الاجتماعي في التغيير السياسي وبالأخص في السودان 
تستتد هذه النظرية على الافتراضات الآتية: أن أعضاء الجمهور فاعلون الأنياعات في

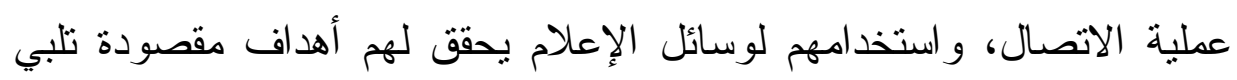
توقعاتهم. 1- الربط بين إثباع حاجات معينة واختيار وسيلة إعلام محددة يرجع إلى الجمهور نفسه وتحدده الفروق الفردية.

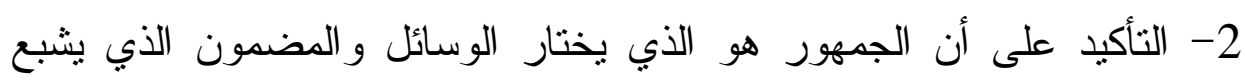

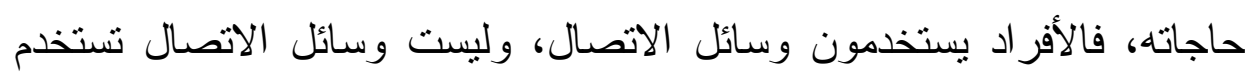
الجمهور - الجن

$$
\text { وقد تم تطوير ها في عام (1974م) على النحو التالي: }
$$

1- يتزتب على ذلك أن كثير من استخدامات الوسيلة يمكن إدر اكها كهدف

$$
\text { موجه. }
$$

2- يربط الجمهور الحقيقي الحاجة بالوسيلة الإعلامية التي اختارها. 3- يمكن استخدام الوسيلة الإعلامية لكسب نسبة عالية من الاثباعات. 4- لا يمكن الاعتماد على محتوي الوسيلة فقط كمؤشر لدرجة الإثباع.

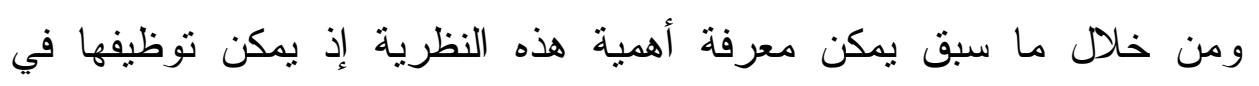

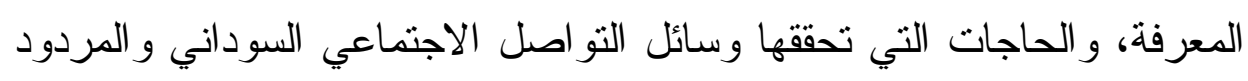
النفسي و الاجتماعي من الستخدامها، و والحاجة إلى الآنتماء، و والطمأنينة و الاستقر ار، وحاجة المستخدم السوداني إلى تأكيد الذات. 2- نظرية الاعتماد على وسائل الإعلام:

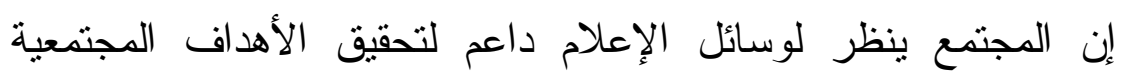

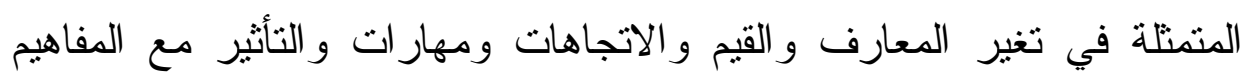




\section{تأثيمر وسائه التواصله الاجتماعي في التغيير السباسي بالسودان}

الاجتماعية والاقتصادية والسياسية ونقل القضايا بصورة مكثقة لتغير أثمل لبعض المفاهيم الاجتماعية، وكثف الغموض الناتج عن نقص المعلومات في حدث معين أو التفسير الواضح للحدث أو زيادة المعلومات في حادثة معينة، وكذلك تكوين رأي لدى الجمهور ، كما أن ترتيب الأولويات، الذي تعتمده وسائل الإعلام في إير از قضايا معينة، وتقوم بنفس الوقت بإخفاء بعض المعلومات التي تشكل أهمية كبيرة لدى الجمهور جر اء تسليط الضوء عليها. من الأهداف الرئيسية لنظرية الاعتماد على وسائل الإعلام الكثف عن الأسباب التي تجعل لوسائل الإعلام أحياناً أثار اً قوية ومباشرة وفي أحئه أحيان أخري تكون لها تأثير ات غير مباشرة وضعيفة نوعاً ما. تقوم علاقات الاعتماد على الى وسائل الإعلام على ركيزتين أساسيتين هما: الأهداف و المصادر وثتقسم إلى المصدر الأول جمع المعلومات، و المصدر الثاني تتسيق المعلومات التي تم جمعها بالزيادة والنقصان، و المصدر الثالث نشر المعلومات أو القدرة على توزيعها إلى جمهور غير محدد. وتستتد هذه الدر اسة على سلوك جمهور و لاية الخرطوم، فالمدخل الوظيفي يركز على مكانة وسائل التو اصل الاجتماعي في حياة المجتمع السوداني، ومن خلال النظرية يمكن الاعتماد على ربط وسائل الإعلام و المجتمع والنظٍ الاجتماعية فهي تحاول فهم الإعلام و الجمهور، ويمكن من خلا هذه النظرية

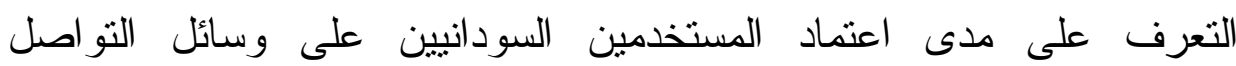
الاجتماعي و الذي ساعد على إحداث التغيير السياسي في السودان ويظهر ذلك في التغيير السياسي الذي حدث في السودان من حكومة شمولية إلى ديمقر اطية. 
عرفت بأنها مجموعة من الأنماط من الاتصال الآكتروني من خلا

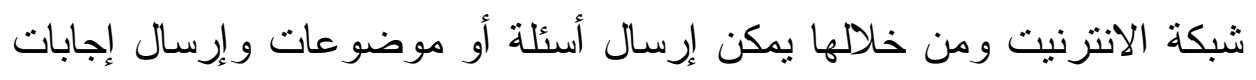

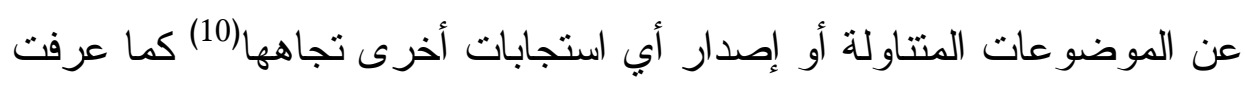

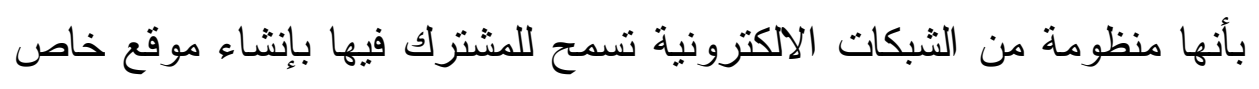

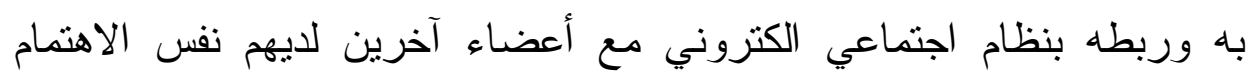

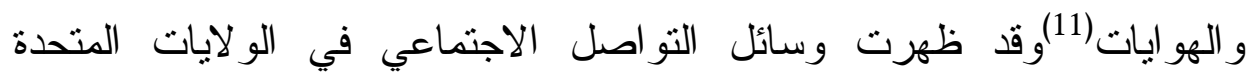

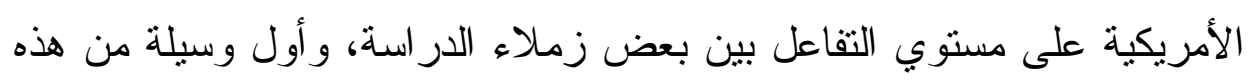

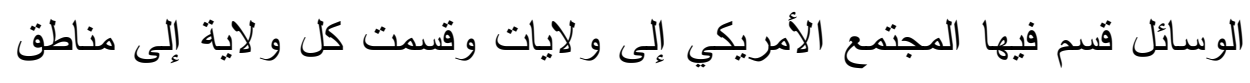

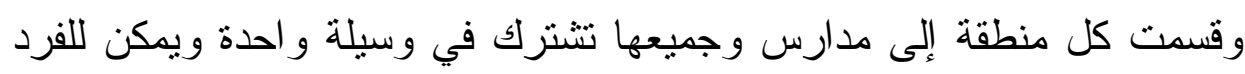

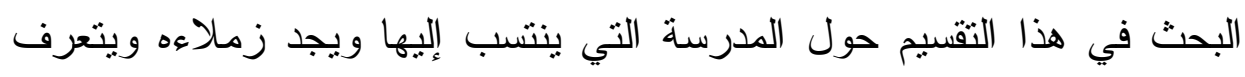
على أصدقاء جدد ويتفاعل معهم عبر هذه الثبكة.

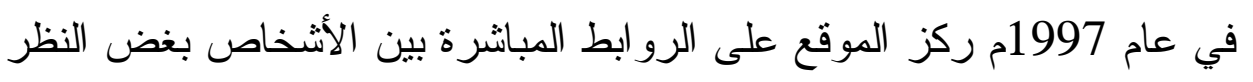

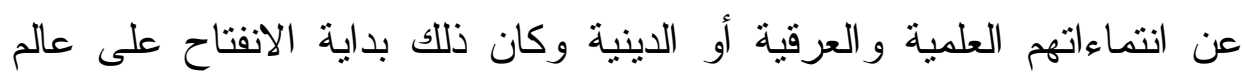
التو اصل الاجتماعي بدون حدود (12). أنواع شبكات التواصل الاجتماعي:

الفيس بوك: هي شبكة اجتماعية استأثرت بقبول وتجاوب كبير من الناس

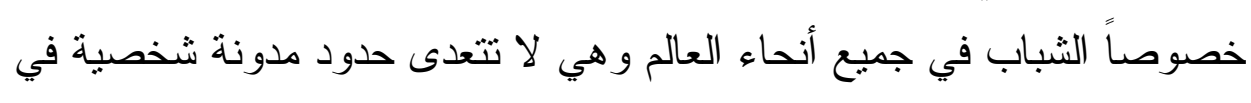
بداية نثأتها في عام (2004م) في جامعة (هارفارد) في الولايات المتحدة

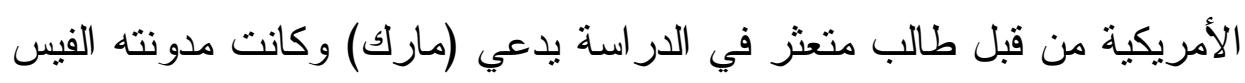

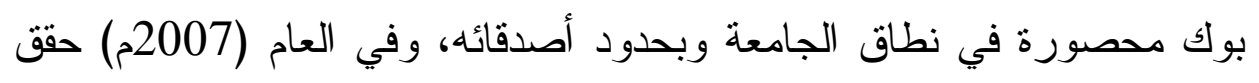

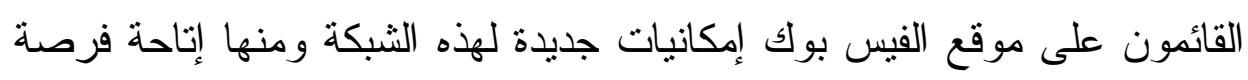

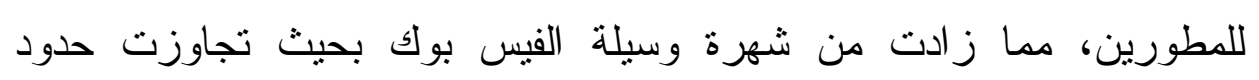


تأثير وسائه التواصله الاجتماعي في التغيير السباسي بالسودان

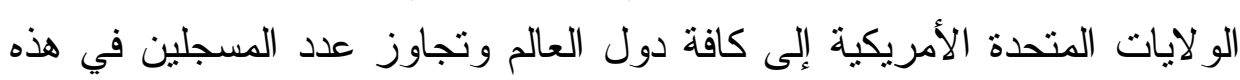
الثبكة في العام(2010م) النصف مليار شخص، وتحتل شبكة الفيس بوك حالياً المركز الثالث بعد موقعي غوغل ومايكروسوفت (13). توتير: هو إحدى شبكات التو اصل الاجتماعي التي انتترت في السنوات الأخيرة ولعبت دوراً كبيراً في الأحداث السياسية في كثير من البلاد، وخاصة في منطقة الثرق الأوسط وتصدرت هذه الثبكة في الآونة الأخيرة، موقعاً رئيساً في أحداث ما يسمى بالربيع العربي، وهي الفيس بوك وتوتير و اليوتيوب وأخذ المصطلح اسمه من تويت الذي يعني التغريدة واتخذ من العصفورة رمزاً له، بلهي وهي خدمة مصغرة تسمح للمغردين بإرسال رسائل قصيرة لا تتعدى (40)

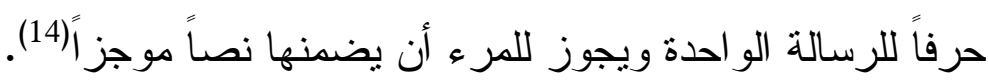
اليوتيوب: هو موقع لمقاطع الفيديو متفرع من غوغل يتيح إمكانية التحميل عليه أو منه لعدد هائل من مقاطع الفيديو، تأسس من قبل ثناثة موظفين كانو ا يعملون في شركة (باى بال) في العام (2005م) في ولاية كاليفورنيا الأمريكية، ويعتمد اليوتيوب في عرض المقاطع المتحركة على (أدوب فلاش) ويثمل مقاطع متعددة من أفلام السينما و التلفزيون و الفيديو (15). الواتساب: هو إحدى التطبيقات التي يمكن تحميلها على الأجهزة الذكية ويتيح تبادل الرسائل الفورية مع المستخدمين الآخرين المشاركين، تأسست شركة و اتساب في العام (2009م) وتحرص هذه الثركة على وضع خاصية الأمان

و الخصوصية على درجة عالية من الحرفية(16). خصائص وسائل التو اصل الاجتماعي: 1- المشاركة: وسائل التو اصل الاجتماعي تثجع المشاركات وردود الأفعال من الأشخاص. - من 


\section{د. برر الدين علي حر حممد \\ 2- الافتاح: معظم وسائل الإعلام عبر وسائل التو اصل الاجتماعي تقدم

$$
\text { خدمات مفتوحة. }
$$

3- الأصدقاء والعلاقات : و هم بمثابة الأشخاص الذين يتعرف عليهم الثخص

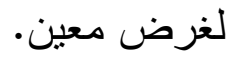

4- البومات الصور : تتيح شبكات التو اصل لمستخدميها إنشاء عدد لا نهائي

$$
\text { من الألبومات. }
$$

5- المجتمع: تسمح للمجتمعات المحلية بتشكيل مواقعها الخاصة بسرعة

$$
\text { و التو اصل بشكل فعال. }
$$

6- الترابط: عبارة عن شبكة اجتماعية متر ابطة بعضها مع بعض وذلك

عبر الوصلات و الرو ابط التي توفرها صفحات تلك المو اقع (17).

إجراعات الار اسة الميدانية:

أداة الدراسة: اعتمدت الدراسة الاستبانة كأداة لجمع البيانات، وهي أداة البحث التي تجمع البيانات من خلال عينة الدراسة وهي تحتوي على أسئلة علمية تتعلق بموضوع الدراسة وشملت على(14) سؤالاً مغلقاً و إعطاء خيار ات فيها لأفر اد عينة الدر اسة.

اختبار صدق الاستبانة: أعتمد الصدق على أسلوبين هما: (أ) الصدق الظاهري: وفي هذا الخصوص قام الباحث بدارسة صحيفة الاستبانة بعد تصميمها للتأكد من أن الأسئلة متصلة جميعها وتم حذف الأسئلة الغير

مهمة. وللتأكد من صدق الاستمارة نم عرضها على عدد من المحكمين (18). (ب) الصدق التجريبي: نم عن طريق وضع أسئلة تأكيدية لقياس نفس الثيء بأسلوبين مختلفين، كما أعتمد الباحث على الاتساق الداخلي بين إجابات الأسئلة المتر ابطة، وكانت نسبة الصدق لعامل صدق 92.3\% تم أخذ مجموعة من الأفر اد 10\% من العينة، تم إرسال نفس الاستبانة التي حصلت عليها وجد أن 
معامل الاتساق الداخلي 93.1 \% وهو معامل مرتفع ذو دلالة علمية عالية ويزيد الاطمئنان على صلاحية الاستبانة للار اسة.

\section{المعالجة الإحصائية:}

أعتمد أسلوب التحليل على استخر اج التكرارات والنسب وبعض الاختبارات البسيطة وفقاً لأسئلة الدر اسة و أهدافها، باستخدام موقع (Google Form)، وهي خاصية من خصائص محرر المستتدات المدمج بخدمة (Google Drive)، وقد تم استخدام نماذج غو غل في عمل الاستبانة. عرض وتفسير نتائج الاراسة الميدانية: جدول رقم (1) يبين نوع العينة

\begin{tabular}{|c|c|c|}
\hline النسبة المئوية & التكرارات & الفئات \\
\hline$\% 71,4$ & 300 & ذكر \\
\hline$\% 28,6$ & 120 & أنثي \\
\hline$\% 100$ & 420 & المجموع \\
\hline
\end{tabular}

من الجدول أعلاه يتضح مشاركة المر أة في عينة الدر اسة بحجم يعتبر مقبو لاً، بعكس بعض المجتمعات التي تكاد تكون مشاركة المر أة قليلة في الإجابة عن الاسنبانات التي تطرح للار اسة، وفي هذه الدراسة تمت المشاركة بنسبة مقبولة وبالأخص أن استخدام المرأة السودانية لوسائل التواصل الاجتماعي قد ازداد بالأخص خلال الاحتجاجات المطالبة بالتغيير وظهر مسمي (الكنداكة) وهو مسمى كان متداولاً من قبل وصعد خلال فترة الاحتجاجات مؤكداً دور المرأة السودانية خلال هذا التغيير السياسي في السودان. جدول رقم (2) يوضح المستوى التعليمي لأفر اد العينة

\begin{tabular}{|c|c|c|}
\hline ثانوي & \multicolumn{2}{|c|}{} \\
\hline جامعي & 30 & التكرارئ \\
\hline
\end{tabular}

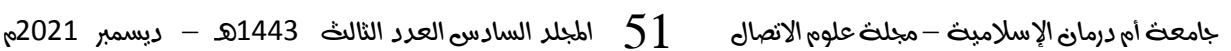




\begin{tabular}{|c|c|c|}
\hline & ربنة علد & \\
\hline$\% 38$ & 160 & فوق الجامعي \\
\hline$\% 100$ & 420 & المجموع \\
\hline
\end{tabular}

يلاحظ أن نسبة الجامعي وفوق الجامعي هي أعلى نسبة مما ساعد الباحث كثيراً في فهم متطلبات الإجابة على الأسئلة المطروحة في الاستبانة، أن أفراد العينة قد أجابو ا على جميع أسئلة الاستبانة، حسب الموجهات التي ذكرتها في الاستبانة

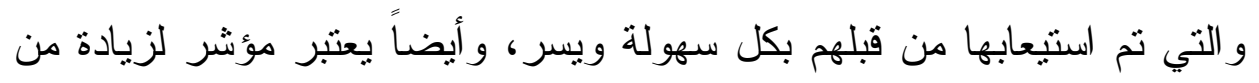
هم في المستوى الجامعي وتم ذلك بفضل التوسع في مجال التعليم العالي الذي شهد إنشاء عدد من الجامعات في ولايات السودان المختلفة التي كانت تختصر في خمس جامعات فقط. وساعد هذا المستوى التعليمي في الالتز ام من قبل المحتجين بمبدأ السلمية وبعيداً عن التخريب لمقدرات السودان. جدول رقم (3) يبين الفئات العمرية لأفر اد عينة الدراسة

\begin{tabular}{|c|c|c|}
\hline النسبة المئوية & التكرارات & الفئات \\
\hline$\% 42,9$ & 180 & 18عام- 28عام \\
\hline$\% 39,2$ & 165 & 29عام -39 عام \\
\hline$\% 12,9$ & 54 & 40عام- 50 عام \\
\hline$\% 5$ & 21 & 50 عام فأكثر \\
\hline$\% 100$ & 420 & المجموع \\
\hline
\end{tabular}

يلاحظ أن غالبية العينة من الثباب فقد بلغت نسبة أعمار هم من 18 عام- 28 عام 42,9\% وهي نسبة عالية، 29 عام-39 بلغت 39,2\% وكما نعلم هناك تصنيفات للثباب تصل إلى سن 49 عاماً ولكن تصنيف اليونسكو حددها في 40 عاماً. و هذا يؤكد ما ذهبت إلبه الدراسات الأخيرة عن المجتمع السوداني بأن غالبية هذا المجتمع يتكون من الفئات العمرية الغالب عليها سن الثباب، مما يساعد كثيرًا على نهضته في المستقبل القادم وبالأخص أن السودان يمنالك ثزوات هائلة تحتاج لأيادي فتية في كل المجالات الزر اعية و الحيو انية و المعدنية في ظل نز اجع دول العالم عن الاعتماد على النفط، و التوجه في المستقبل القادم 
تأثير وسائله التواصلة الاجتماعي في التغيير السباسي بالسودان

نحو الزر اعة، وساعدت أيضاً هذه السن الثبابية على تحمل عناء الاحتجاجات وتحمل المشقة والقوة المفرطة التي استخدمنها قوات نظام الإنقاذ لإيقاف

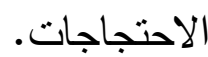

جدول رقم (4) يبين أكثر وسائل التواصل الاجتماعي استخداماً من قبل المستخدمين

\begin{tabular}{|c|c|c|}
\hline النسبة المئوية & التكرارات & الفئات \\
\hline$\% 24 ، 3$ & 102 & اليوتيوب \\
\hline$\% 71 ، 4$ & 300 & الفيس بوك والواتس اب \\
\hline$\% 2.8$ & 12 & توتير \\
\hline$\% 1.5$ & 6 & السناب شات \\
\hline$\% 100$ & 420 & المجموع \\
\hline
\end{tabular}

يتضح من الجدول أعلاه أن الفيس بوك والواتساب هما من الأكثر الوسائل استخداماً من قبل السودانيين لسهولة ويسر استخدامهما وقلة الميجابايت في استهالاكها من الانترنيت بخلاف اليوتيوب الذي يكلف الكثير من الاستهلاك في شبكة الانترنيت ويلاحظ أن اسناب شات استخدمها قليل جداً وسط السودانيين خلاف بقية وسائل التو اصل الاجتماعي.

جدول رقم (5) يوضح أكثر الأسباب لاستخدام وسائل التو اصل الاجتماعي من قبل أفراد العينة

\begin{tabular}{|c|c|c|}
\hline النسبة المئوية النية & التكرارات & الفئات \\
\hline$\% 18.8$ & 79 & الاطلاع على المستجدات الراهنة على المستوى المحلي والإقليمي والدولي. \\
\hline$\% 70 ، 2$ & 295 & التفاعل مع قضايا الوطن. ا \\
\hline$\% 11$ & 46 & التسلية وتتضية أوقات الفراغ. \\
\hline$\% 100$ & 420 & 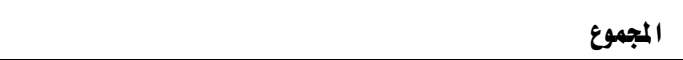 \\
\hline
\end{tabular}

أحداث السودان المتلاحقة في الحرالك نحو التغيير السياسي بإسقاط حكومة الإنقاذ التي سيطرت على السودان طو ال الثلاثين عاماً والتي جعلت البلاد في تمزق مستمر بانفصال جنوب الوطن وازدادت الضغوط الاقتصادية و الاستبداد

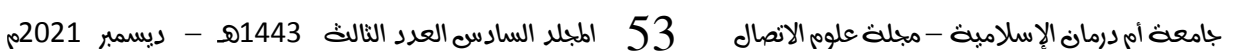




\section{د. برر الدين علي حر حممد}

السياسي ترك المو اطن السوداني بالداخل و الخارج متابعاً للأحداث التي آلت إليها البلاد وبالأخص في فترة هذه الدر اسة للعام 2021م مما اضطر الجميع لمتابعة قضايا الوطن السياسية و الاقتصادية لذا جاءت فئة متابعة القضايا الوطنية من من الوهن أولويات المستخدم للفيس بوك و الو اتساب و غيرها من وسائل التو اصل الاجتماعي.

جدول رقم (6) يوضح درجة مو افقة أفر اد الدر اسة على أن وسائل التو اصل الاجتماعي قد ساعدت على نجاح التغيير السياسي في السودان

\begin{tabular}{|c|c|c|}
\hline النسبة المئوية & التكرارات & الفئات \\
\hline$\% 55.5$ & 233 & أوافق \\
\hline$\% 25$ & 105 & أوافق لحد ما \\
\hline$\% 19.5$ & 82 & لاأوافق \\
\hline$\% 100$ & 420 & المجموع \\
\hline
\end{tabular}

و اقق أفر اد عينة الدراسة على أن وسائل التو اصل الاجتماعي أدت إلى نجاح التغيير السياسي من خلال التجمعات للمتظاهرين و اختيار مراكز للتجمهر و الهناف ضد النظام الحاكم، ولم تكن هنالك وسيلة أخرى لإعلان التحرك إلا عن طريق استخدام وسائل التواصل الاجتماعي المختلفة لتو اصل الثوار و المتظاهرين في تحديد ساعة الصفر للانطلاق بالهتاف و التحرك السلمي و اختيار شعار لكل تظاهرة. جدول رقم (7) يين درجة المو افقة على أن وسائل التو اصل الاجنماعي مكنت النشطاء السياسيين المعارضين من طرح أفكار هم بضرورة التغيير السياسي في السودان

\begin{tabular}{|c|c|c|}
\hline النسبة المئوية & التكرارات & الفئات \\
\hline$\% 60 ، 5$ & 254 & أوافق \\
\hline$\% 30$ & 126 & أوافق لحد مـا \\
\hline$\% 9.5$ & 40 & لاأوافق \\
\hline$\% 100$ & 420 & المجموع \\
\hline
\end{tabular}




\section{تأيثير وسائل التواصله الاجتماعي في التغيير السباسيع بالسودان}

لم يجد النشطاء السياسيين و المعارضين وسائل متاحة أمامهر سوى أن يلجؤوا لاستخدام وسائل التو اصل الاجتماعي لطرح أفكار هم للتغبير السياسي للمحتجين ضد سياسات حكومة الإنقاذ لأن كل وسائل الإعلام التقليدية كانت تتحدث بلسان النظام متجاهلة تماماً ما يدور من حر الك في الثار ع السوداني ومنعت سلطات نظام الإنقاذ هذه الوسائل الإعلامية من تتاول أي أخبار عن هذا الحر الك.

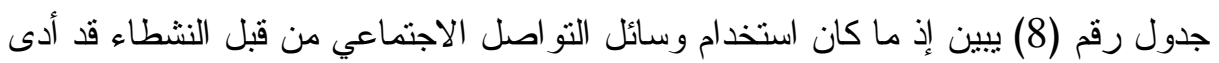
إلى تجاوب و اقتتاع من قبل جمهور المستخدمين في السودان

\begin{tabular}{|c|c|c|}
\hline النسبة المئوية & التكرارات & الفئات \\
\hline$\% 73 ، 1$ & 307 & أوافق \\
\hline$\% 23.5$ & 99 & أوافق لحد ما \\
\hline$\% 3.4$ & 14 & لاأوافق \\
\hline$\% 100$ & 420 & المجموع \\
\hline
\end{tabular}

من الجدول أعلاه يتضح أن استخدام وسائل التواصل الاجتماعي من قبل النشطاء السياسيين وظهرت بر اعتهم في استخدامهم لهذه المنصات لتجاوب الثباب معهم و إقناعهم بضرورة التغيير السياسي بإسقاط حكومة الإنقاذ و اتضح لهؤلاء المستخدمين لهذه الوسائل بفشل النظام الحاكم في جميع الملفات السياسية و الاقتصادية ونشر هم للتوعية السياسية من خلال خطاباتهم المرسلة من وسائل التو اصل الاجتماعي مما أدى إلى إقناع الثباب بالتحرك نحو التغيير • جدول رقم (9) يوضح درجة المو افقة على أن تجاه لأفر اد السلطة الحاكمة لقوة تأثير وسائل

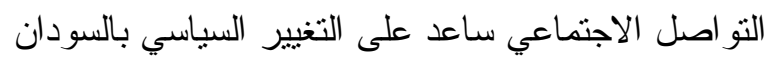

\begin{tabular}{|c|c|c|}
\hline النسبة المئوية & التكرارات & الفئات \\
\hline$\% 54,1$ & 227 & أوافق \\
\hline$\% 26,2$ & 110 & أوافق لحد ما \\
\hline$\% 19,7$ & 83 & لا أوافق \\
\hline$\% 100$ & 420 & المجموع \\
\hline
\end{tabular}

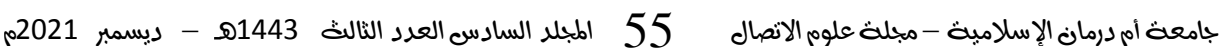




\section{د. برر الرين علي حمدمعد}

من الجدول أعلاه بيضح السلطة الحاكمة تتجاهل الخطابات التي تبث من وسائل

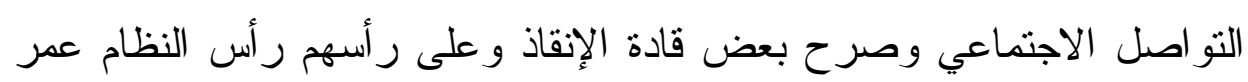

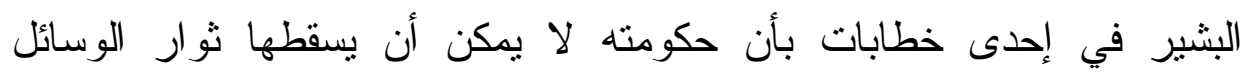

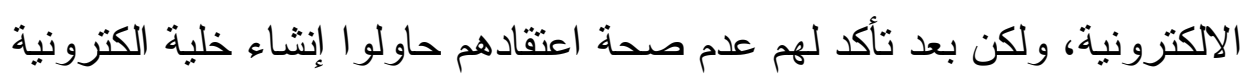

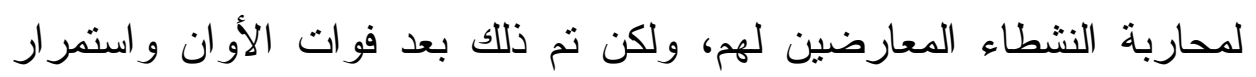

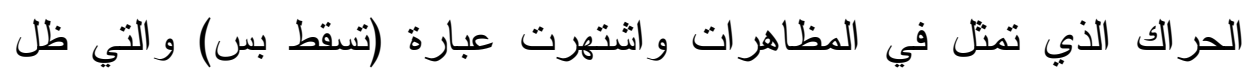

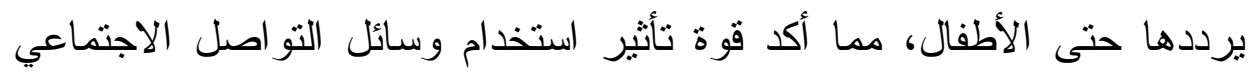

$$
\text { لإحداث تغيير على المجتمع السودان. }
$$

جدول رقم (10) ييين إذ ما كان نأثير استخدام وسائل التو اصل الاجتماعي من قبل النشطاء

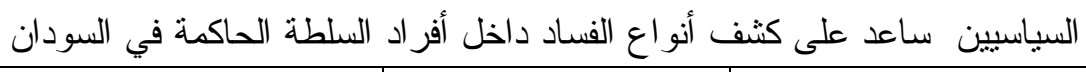

\begin{tabular}{|c|c|c|}
\hline النسبة المئوية & التكرارات & الفئات \\
\hline \%71،9 & 302 & أوافق \\
\hline$\% 25.5$ & 107 & أوافق لعدما \\
\hline \%2، 6 & 11 & لاأوافق \\
\hline$\% 100$ & 420 & الججموع \\
\hline
\end{tabular}

أظهرت بعض المقاطع المصورة الفساد المالي لأفراد النظام الحاكم بتصوير

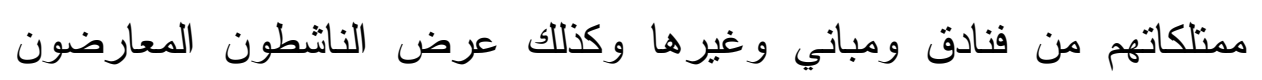

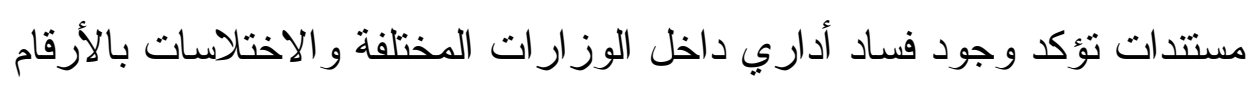

$$
\text { وكذللك الفساد الأخلاقي لأفر اد النظام الحاكم. }
$$

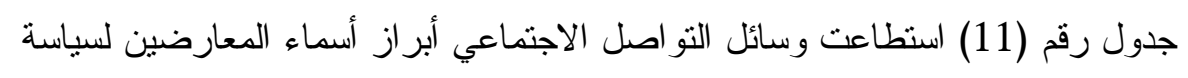

\begin{tabular}{|c|c|c|}
\hline النسبة المئوية & التكرارات & الفئات \\
\hline$\% 64 ، 3$ & 270 & أوافق \\
\hline$\% 21$ & 88 & أوافق لحد ما \\
\hline$\% 14.7$ & 62 & لااوافق \\
\hline$\% 100$ & 420 & المجموع \\
\hline
\end{tabular}

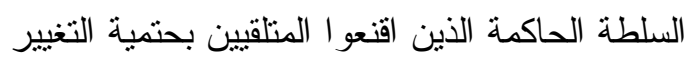

جامعة أم درمان الإسلامية - مجلة علوم الانصال 56 إمبلد السادسع العدد النالغ 1443هـ - ديسمبر 2021م 
تأيثر وسائل التواصل الاجتماعي في التغيير السباسيه بالسودان

ظهرت شخصيات معارضة للنظام الحاكم عبر وسائل التو اصل الاجتماعي كقادة مؤثرين في هذا الحراك بمختلف أعمارهم وكان لهم جمهورهم الذي بنتظر إطلالتهم بعد كل حدث أثثاء التظاهر ات، موضحين كل ما يدور داخل النظام مما زاد درجة الوعي ومؤكدين على ضرورة الحر الك السلمي وعدم الانجر اف نحو العنف الذي قد يعرض البلاد إلى الكثير من المشكلات السياسية والاجتماعية و الفكرية.

جدول رقم (12) ساعدت وسائل التو اصل الاجتماعي على حشد الثباب للنظاهر ات و الاعتصامات ضد نظام الإنقاذ في السودان دون الوسائل التقليدية من إذاعة وصحافة وتلفزيون

\begin{tabular}{|c|c|c|}
\hline النسبة المئوية & التكرارات & الفئات \\
\hline$\% 76.2$ & 320 & أوافق \\
\hline$\% 23 ، 3$ & 98 & أوافق لحد ما \\
\hline$\% .5$ & 2 & لاأوافق \\
\hline$\% 100$ & 420 & المجموع \\
\hline
\end{tabular}

يلاحظ من خلال هذا الجدول في أثناء الحر الك الثعبي لم يكن هناك ظهور يذكر للإعلام التقليدي الحكومي ممنل في الإذاعة و التلفزيون لتغطية الحر الك السياسي في السودان، ولم تتمكن أي وسيلة من هذه الوسائل تتاول أي خبر حتى لو لو قصير عما يحدث في السودان مما اضطر بعض القنوات خارج السودان الاعتماد على مصادر من داخل الحرالك وما يدور في الثشارع، أما الصحف السودانية الورقية فقد تمكنت السلطة من منعها من الكتابة ومن يحاول أن يكتب عن التظاهرات يزج به في السجون التي تكدست بالمعارضين للنظام، ماعدا صحيفة الر اكوبة الإكترونية التي ظلت نواصل التغطية الصحفية للأحداث في 


\section{د. برر الربنه علي حرمحمد}

جدول رقم (13) استطاعت وسائل التو اصل الاجتماعي توثيق الانتهاكات التي تمت ممارستها من قبل نظام الإنقاذ تجاه المنظاهرين السلميين في السودان

\begin{tabular}{|c|c|c|}
\hline النسبة المئوية & التكرارات & الفئات \\
\hline$\% 68.5$ & 288 & أوافق \\
\hline$\% 23,1$ & 97 & أوافق لحد ما \\
\hline$\% 8.4$ & 35 & لاأوافق \\
\hline$\% 100$ & 420 & المجموع \\
\hline
\end{tabular}

بالرغم من محاربة النظام الحاكم لإخفاء الانتهاكات الإنسانية بحجب خدمة شبكة الانتزنيت عن المتظاهرين إلا أنهم تمكنوا من تصوير قوات الثرطة وكتائب الظل التي أسسها على عثمان وهي تدخل إلى البيوت وتمارس كل أنو اع البطش نحو شباب الحرالك و الكثف عن كل هذه الانتهاكات التي تتعارض تماماً مع حقوق الإنسان الذي كفلته كل الدساتير حتى الدستور السوداني. جدول رقم (14) ساعدت وسائل التو اصل الاجتماعي تجمع المهنيين السودانيين من التو اصل لإنل مع الثباب المنظاهرين تجاه التغيير السياسي بالسودان

\begin{tabular}{|c|c|c|}
\hline النسبة المئوية & التكرارات & الفئات \\
\hline$\% 80 ، 9$ & 340 & أوافق \\
\hline$\% 17 ، 4$ & 73 & أوافق لحد ما \\
\hline$\% 1.7$ & 7 & لاأوافق \\
\hline$\% 100$ & 420 & المجموع \\
\hline
\end{tabular}

ساعدت وسائل التو اصل الاجتماعي تجمع المهنبين وهي الجهة المنظمة لحشود المتظاهرين من التو اصل معهم وتحديد زمن ومكان الحر الك بدقة متتاهية طو ال فترة الأربعة شهور وهي المدة التي بعدها سقطت حكومة الإنقاذ ولو لا وسائل التو اصل الاجتماعي لما تم ذلك التو اصل. النتائج: خرجت الدراسة بعدد من النتائج وأهمها: 1-بينت الدراسة أن الفيس بوك و الواتساب هما أكثر وسائل التو اصل الاجتماعي استخداماً من قبل الناشطين. 


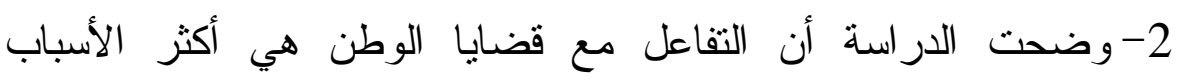

لاستخدام وسائل التو اصل الاجتماعي من قبل أفر اد العينة.

3- كثفت الدر اسة على أن وسائل التو اصل الاجتماعي ساعدت على نجاح

$$
\text { التغيير السياسي في السودان. }
$$

4- أكدت الدراسة أن وسائل التو اصل الاجتماعي مكنت الناشطين السياسيين المعارضين من طرح أفكار هم بضرورة التغيير السياسي في

$$
\text { السودان. }
$$

5- أكدت الدر اسة أن استخدام وسائل التو اصل الاجتماعي من قبل الناشطين

قد أدى إلى تجاوب واقتتاع جمهور المستخدمين في السودان بضرورة

$$
\text { التغبير السياسي. }
$$

6-وضحت الدراسة أن تجاهل أفر اد السلطة الحاكمة لقوة تأثير وسائل

$$
\text { التو اصل الاجتماعي ساعد على التغيير السياسي بالسودان. }
$$

7- أكد أفر اد الدر اسة على تأثثر استخدام وسائل التو اصل الاجتماعي من بن

قبل النشطاء قد ساعد على كثف أنواع الفساد داخل أفراد السلطة

$$
\text { الحاكمة في السودان. }
$$

8-وضحت الدر اسة أن وسائل التو اصل الاجتماعي استطاعت إيراز أسماء

المعارضين لسياسة السلطة الحاكمة الذين اقنعوا المتلقيين بحتمية

$$
\text { التغنيير }
$$

9- بينت الدراسة أن وسائل التو اصل الاجتماعي أسهمت في حشد الثباب

للتظاهر ات والاعتصامات ضد نظام الإنقاذ في السودان دون الوسائل

$$
\text { التقليدية من إذاعة وصحافة وتلفزيون. }
$$




\section{د. بلدر الرين علي حمرحمد}

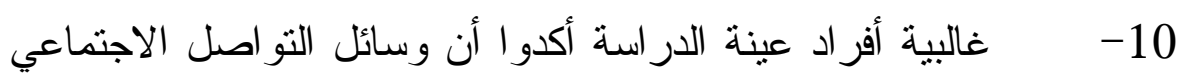
استطاعت نوثيق الانتهاكات التي تمت ممارستها من قبل نظام الإنقاذ تجاه المنظاهرين السلميين في السودان.

التوصيات:

1-ضرورة الاستفادة من الإيجابيات من استخدام وسائل التواصل الاجتماعي من قبل النشطاء السياسيين المستخدمين.

2- على الوسائل الإعلامية في السودان من صحافة و إذاعة وتلفزيون الاهتمام بالقضايا المصيرية للثعب السوداني دون التركيز في تغطيتها الإعلامية على الأنظمة الحاكمة فقط.

3- على النظام السياسي الذي يحكم السودان مستقبلاً منح الاهتمام الكافي لما لـأل

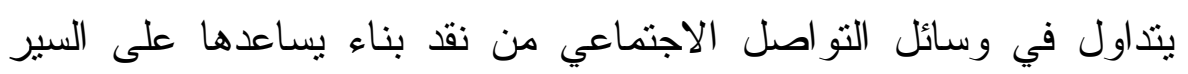

$$
\text { بخطي سليمة تجاه حكم السودان. }
$$

4- ضرورة الاهتمام بقضايا الثباب السوداني الني نطرح من خلال وسائل

$$
\begin{aligned}
& \text { التو اصل الاجتماعي. } \\
& \text { الهو امش: }
\end{aligned}
$$

1- سمير محمد حسين، بحوث الإعلام الأسس والمبادئ، القاهرة: -عالم الكتب،

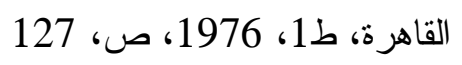

2- ذوقان عبيدات وعبد الرحمن عس وكايد، الحقان، الحق، البحث العلمي مفهومه وأدواته،

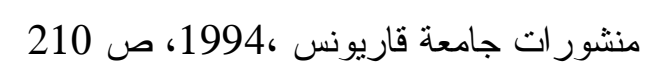

3- إبر اهيم الحميدان، الإقناع و التأثير - در اسلة تأصيلية، مجلة جامعة الإمام ال عدد

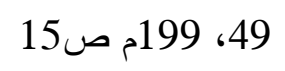

4- مقلد إبراهيم، ربيع محمد محمود، موسوعة العلوم السياسية، الكويت: جامعة

$$
\text { الكويت، 1995م، ص } 47
$$




\section{تأثير وسائله التواصل الاجتماعي في التغيير السباسي بالسودان}

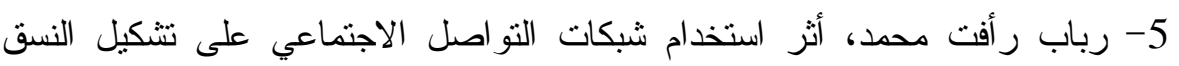

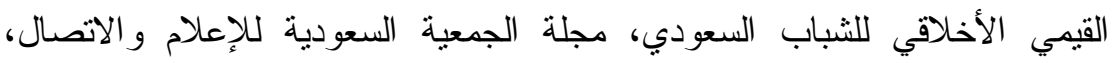

$$
\text { الرياض، 2014م ص } 10 .
$$

6- أسامة غازي مدني،دور شبكات التواصل الاجتماعي في تشكيل الر أي العام لدى

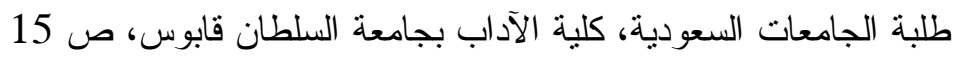
7- بدر الدين علي حمد، اتجاهات مستخدمي مواقع التواصل الاجتماعي نحو انتهاكات الخصوصية للأفر اد المستخدمين -در اسة ميدانية على عينة المستخدمين السودانيين بو لاية الخرطوم للعام 2017م مجلة كلية الإعلام - جامعة أم درمان الإسلامية العدد عليه

$$
\text { الثاني } 2017
$$

8- حسن قطيم طماح، الاستخدامات السياسية لمواقع التواصل الاجتماعي، رسالة

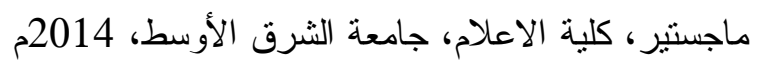

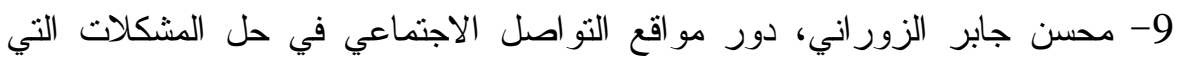
تو اجه طلاب التربية العملية، رسالة دكتور اه، جامعة أم القرى، المملكة العربية

$$
\text { السعودية، 2013م، صو طبه }
$$

10- مريع غزل، تأثير مواقع التواصل الاجتماعي على تتمية الوعي السياسي لدى

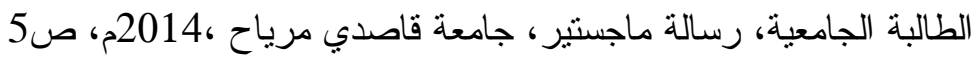
11- رندا رفيق محمود، الاضطر ابات السلوكية وعلاقتها بأساليب التتشئة الأسرية،

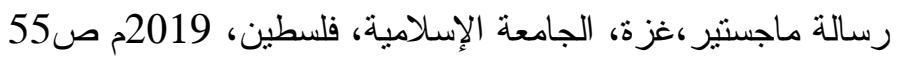

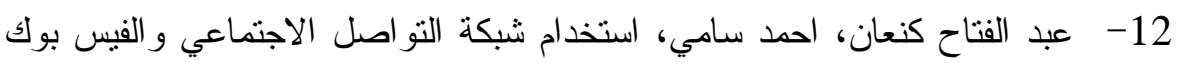

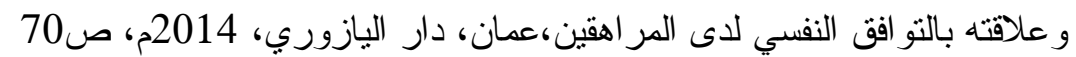

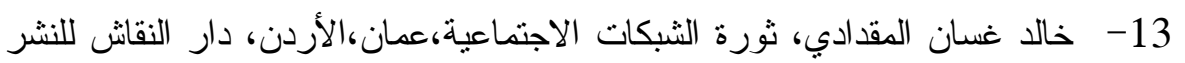
2012، 20 14- عبدالحافظ احد نواصل الثباب الجامعي من خلال الثبكات الاجتماعية، المؤتمر العلمي، وسائل الإعلام أدوات تغيير وتتعبير، كلية الإعلام، جامعة البتر اه،

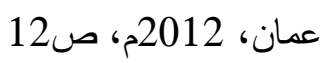




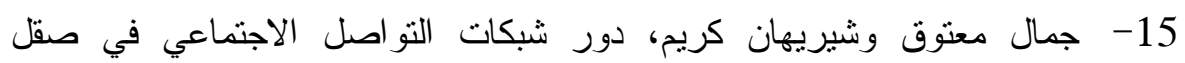
سلوكيات وممارسات الافر اد في المجتمع، ورقة عمل للملتقي الدولي حول شبكات

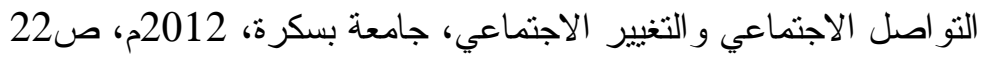
16- رضا عبد الواحد استخدامات الثباب الجامعي لموقع اليوتيوب على شئليكة الانترنيت المؤتمر الأول الاعلام الجديد، تكنولوجيا جديدة، جامعة البحرين ابريل

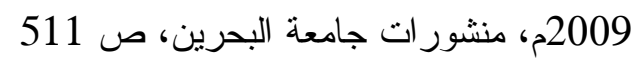
17- دكتور سيف الدين حسن العوض، أستاذ الإعلام بجامعة ام درمان الإسلامية

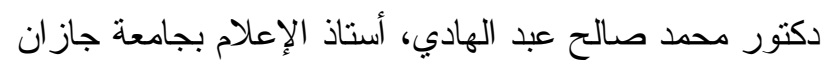

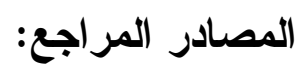

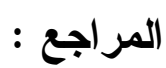

1- سمير محمد حسين، بحوث الإعلام الأسس و المبادئ، القاهرة: -عالم

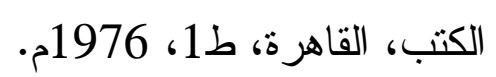
2-ذوقان عبيدات وعبد الرحمن عدس وكايد الحق، البحث العلمي مفهومه و أدو اته، منشور ات جامعة قاريونس، 1994م. 3-إبر اهيم الحميدان، الإقناع و التأثير - در اسة تأصيلية، مجلة جامعة الإمام

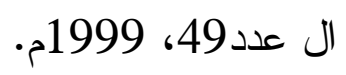
4-على عبد الفتاح كنعان، احمد سامي، استخدام شبكة التو اصل الاجتماعي و الفيس بوك وعلافته بالتو افق النفسي لدى المر اهقين،عمان، دار اليازوري، 2014 5-خالد غسان المقدادي، ثورة الثبكات الاجتماعية،عمان،الأردن، دار النقاش للنشر 2012، الرسئل الجامعية: - (ائل 1-أسامة غازي مدني، دور شبكات التواصل الاجتماعي في تشكيل الرأي العام لدى طلبة الجامعات السعودية، كلية الآداب بجامعة السلطان قابوس، 2016م 
2- حسن قطيم طماح، الاستخدامات السياسية لمواقع التواصل الاجتماعي، رسالة ماجستير ، كلية الاعلام، جامعة الثرق الأوسط، 2014م

3-محسن جابر الزور اني، دور مواقع التواصل الاجتماعي في حل المشكلات التي تواجه طلاب التربية العملية، رسالة دكتور اه، جامعة أم القرى، المملكة دورية العربية السعودية، 2013م 4-مريع غزل، تأثير مو اقع التو اصل الاجتماعي على تتمية الوعي السياسي لدى الطالبة الجامعية، رسالة ماجستير ، جامعة قاصدي مرياح ،2014م 5-رندا رفيق محمود، الاضطر ابات السلوكية وعلاقتها بأساليب التنشئة الأسرية، رسالة ماجستير ، غزة، الجامعة الإسلامية، فلسطين، 2019م

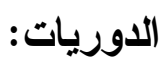

1-إير اهيم الحميدان، الإقناع و التأثثر - در اسة تأصيلية، مجلة جامعة الإمام

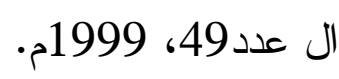

2- أرباب رأفت محمد، أثز استخدام شبكات التو اصل الاجتماعي على نتكيل النسق القيمي الأخلاقي للشباب السعودي، مجلة الجمعية السعودية للإعلام و الاتصال، الرياض، 2014م 3-بدر الدين علي حمد، اتجاهات مستخدمي مواقع التواصل الاجتماعي نحو انتهاكات الخصوصية للأفر اد المستخدمين -در اسة مبدانية على عينة المستخدمين السودانيين بو لاية الخرطوم للعام 2017م مجلة كلية الإعلام - جامعة أم درمان الإسلامية العدد الثاني 2017 


$$
\text { د. بلر الربن علي حر حمد }
$$

$$
\text { المؤتمرات: }
$$

4-عبد الحافظ احمد نواصل الثباب الجامعي من خلال الثبكات الاجتماعية، المؤتمر العلمي، وسائل الإعلام أدوات تغيير وتعبير، كلية الإعلام، جامعة

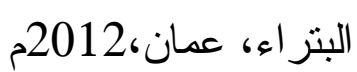

5-جمال معتوق وشيريهان كريم، دور شبكات التواصل الاجتماعي في صقل سلوكيات وممارسات الافراد في المجتمع، ورقة عمل للملتقي الدولي حول شبكات التو اصل الاجتماعي و التغيير الاجتماعي، جامعة بسكرة، 2012م، ص222 6-رضا عبد الواحد استخدامات الثباب الجامعي لموقع اليونيوب على شبكة الانترنيت المؤتمر الأول ن الاعلام الجديد، تكنولوجيا جديدة، جامعة البحرين ابريل 2009م، منشور ات جامعة البحرين، ص 511 